\title{
Quantitative Evaluation of the Mechanism of Electroreduction of Benzoyl Cyanides
}

\author{
Norma A. Macías-Ruvalcaba and Dennis H. Evans. \\ Department of Chemistry, University of Arizona, Tucson, AZ 85721, U.S.A.
}

\section{Supporting Information}

\section{General figure caption for Figures S1-S12.}

Comparison of simulation (symbols) to background-corrected experimental voltammograms (full curves) of 6-8 under various conditions. (See the figures themselves for specific conditions). 0.100 M Tetrabutylammonium hexafluorophosphate in acetonitrile. Glassy carbon working electrode $\left(0.0814 \mathrm{~cm}^{2}\right)$. Simulation parameters are listed in Tables 1-4 of the paper. For acetonitrile solutions the total solution resistance was $140 \Omega$ of which $120 \Omega$ was compensated electronically and $20 \Omega$ was included in the simulation. For DMF the total solution resistance was $280 \Omega$ of which $240 \Omega$ was compensated electronically and $40 \Omega$ was included in the simulation. All voltammograms obtained at $298 \mathrm{~K}$. 


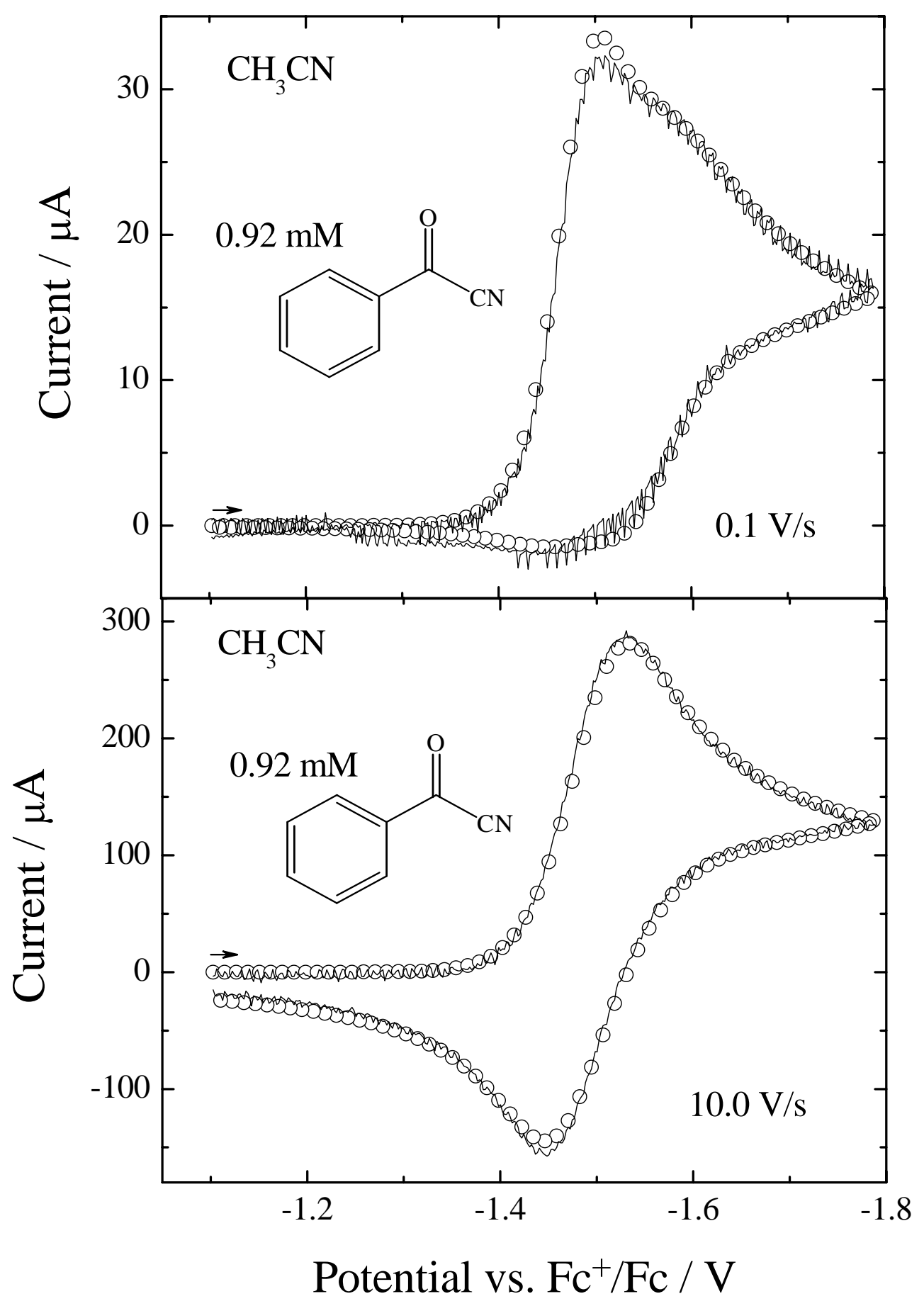

Figure S1 


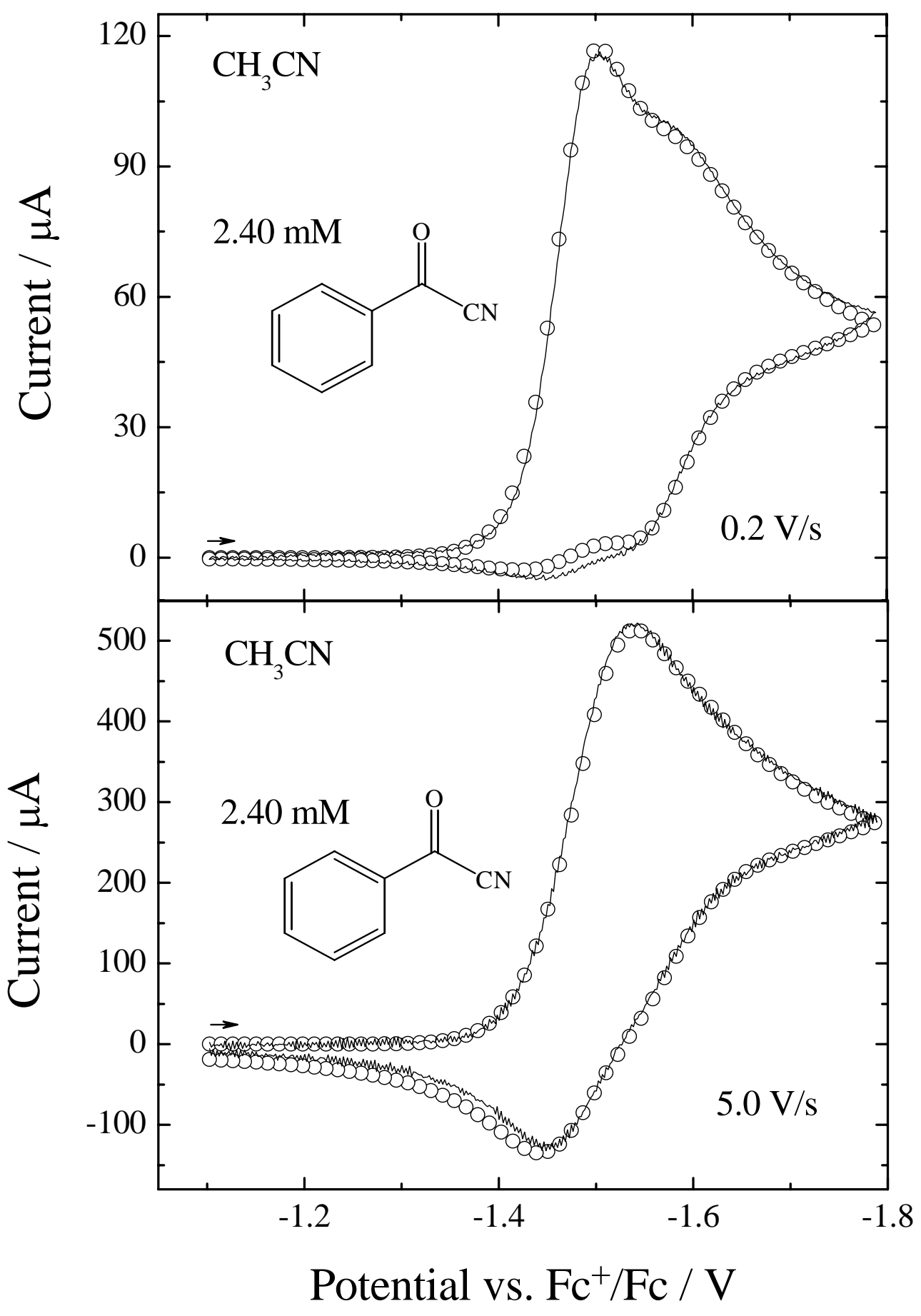

Figure S2 


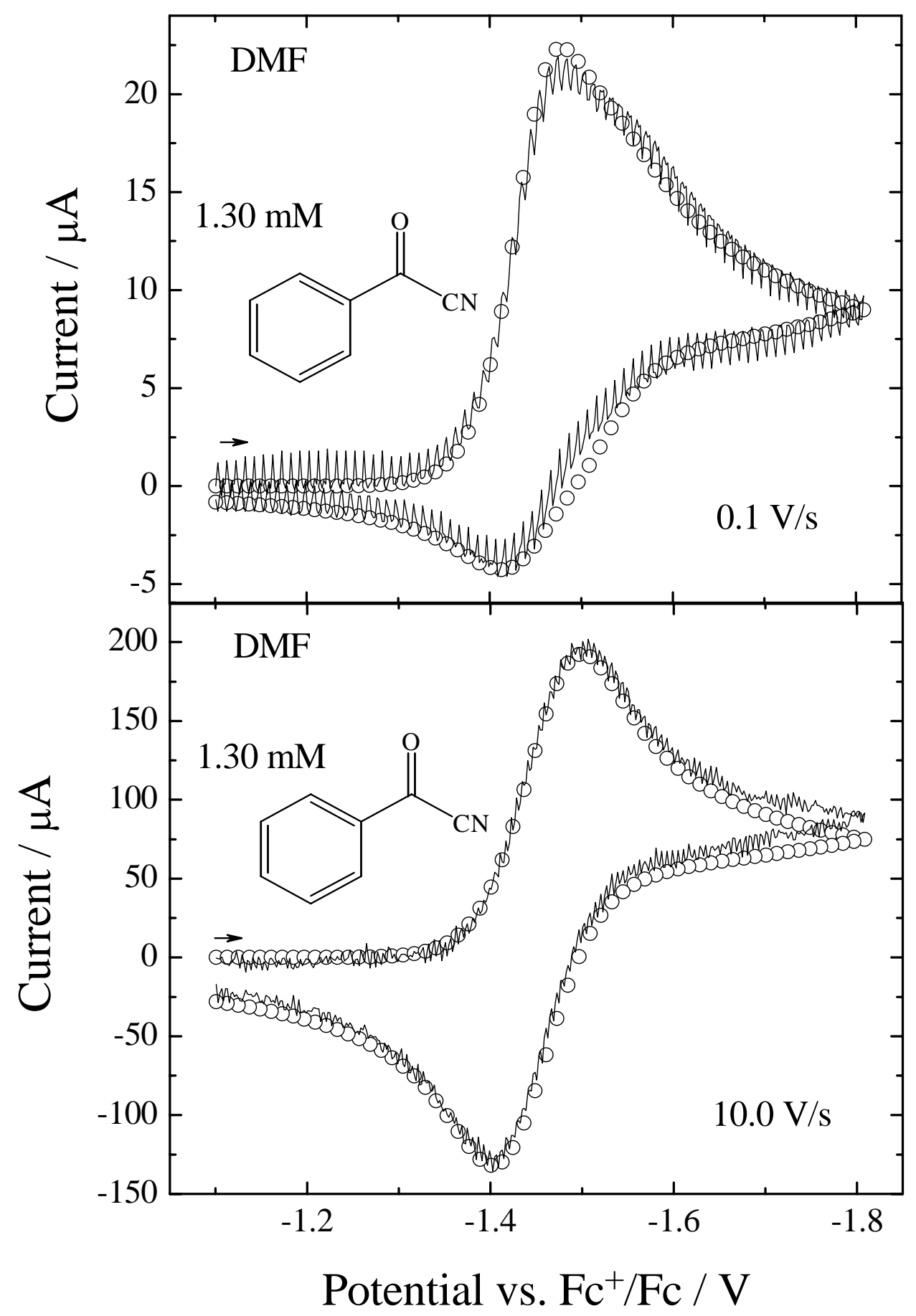

Figure S3 


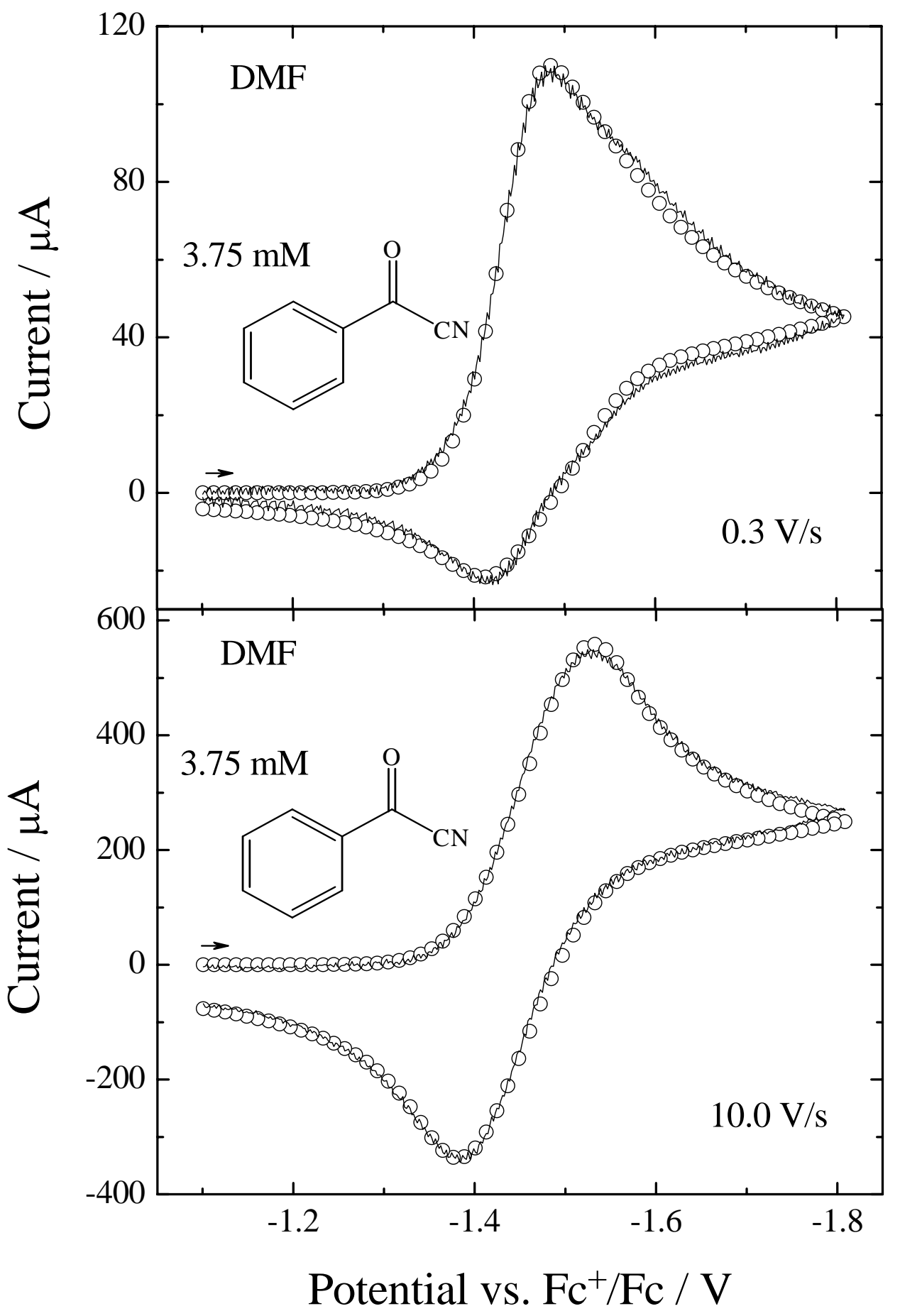

Figure S4 


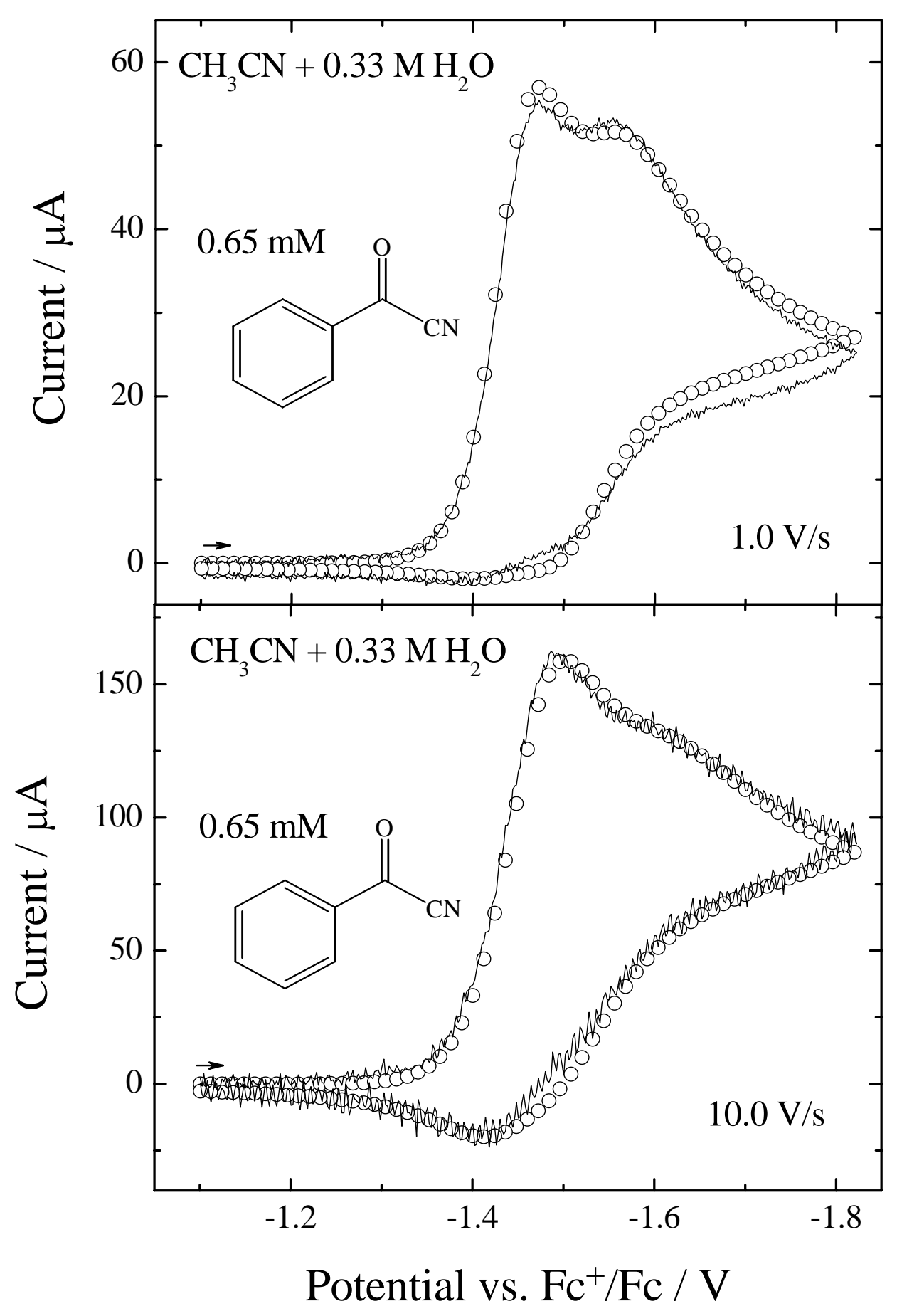

Figure S5 


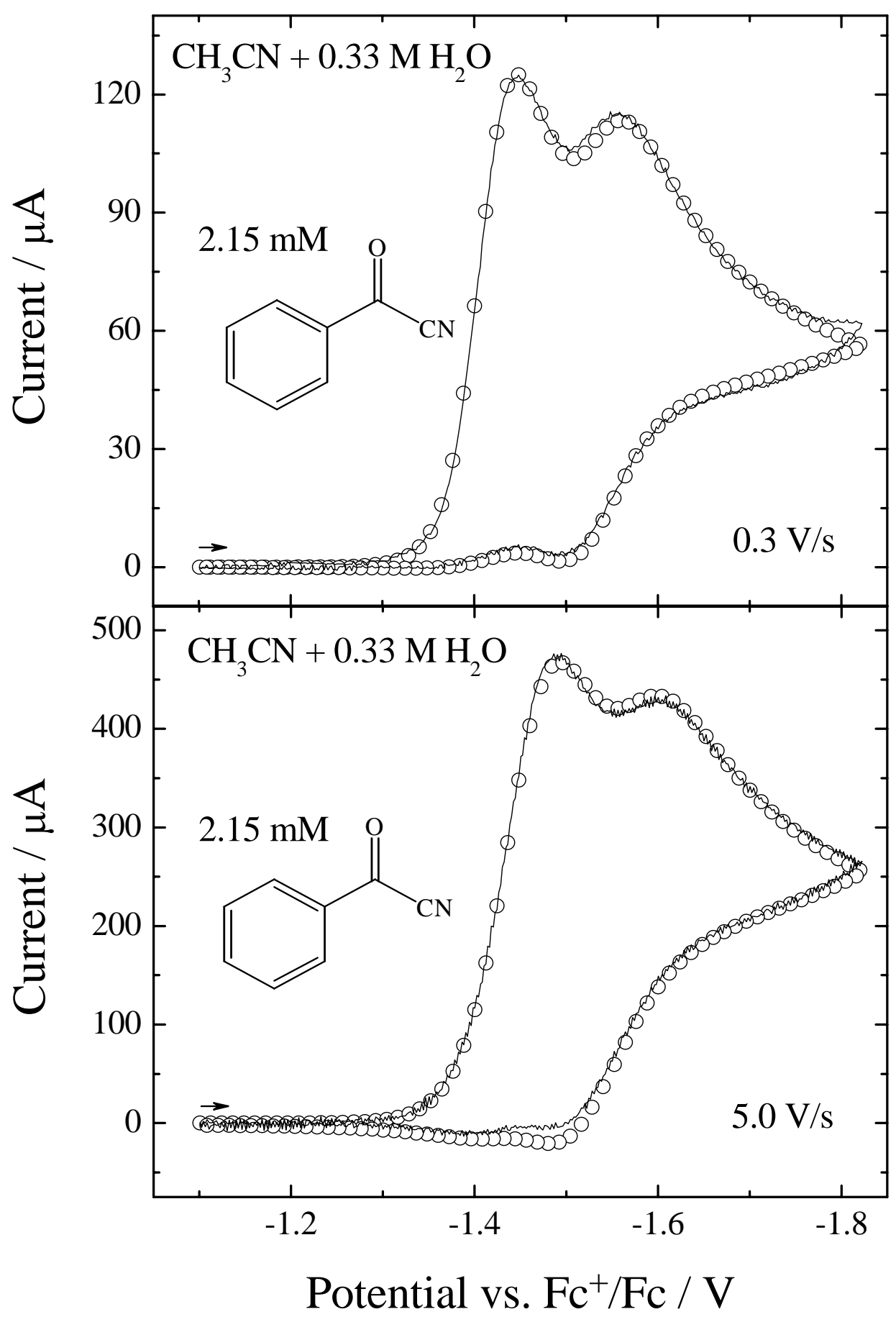

Figure S6 


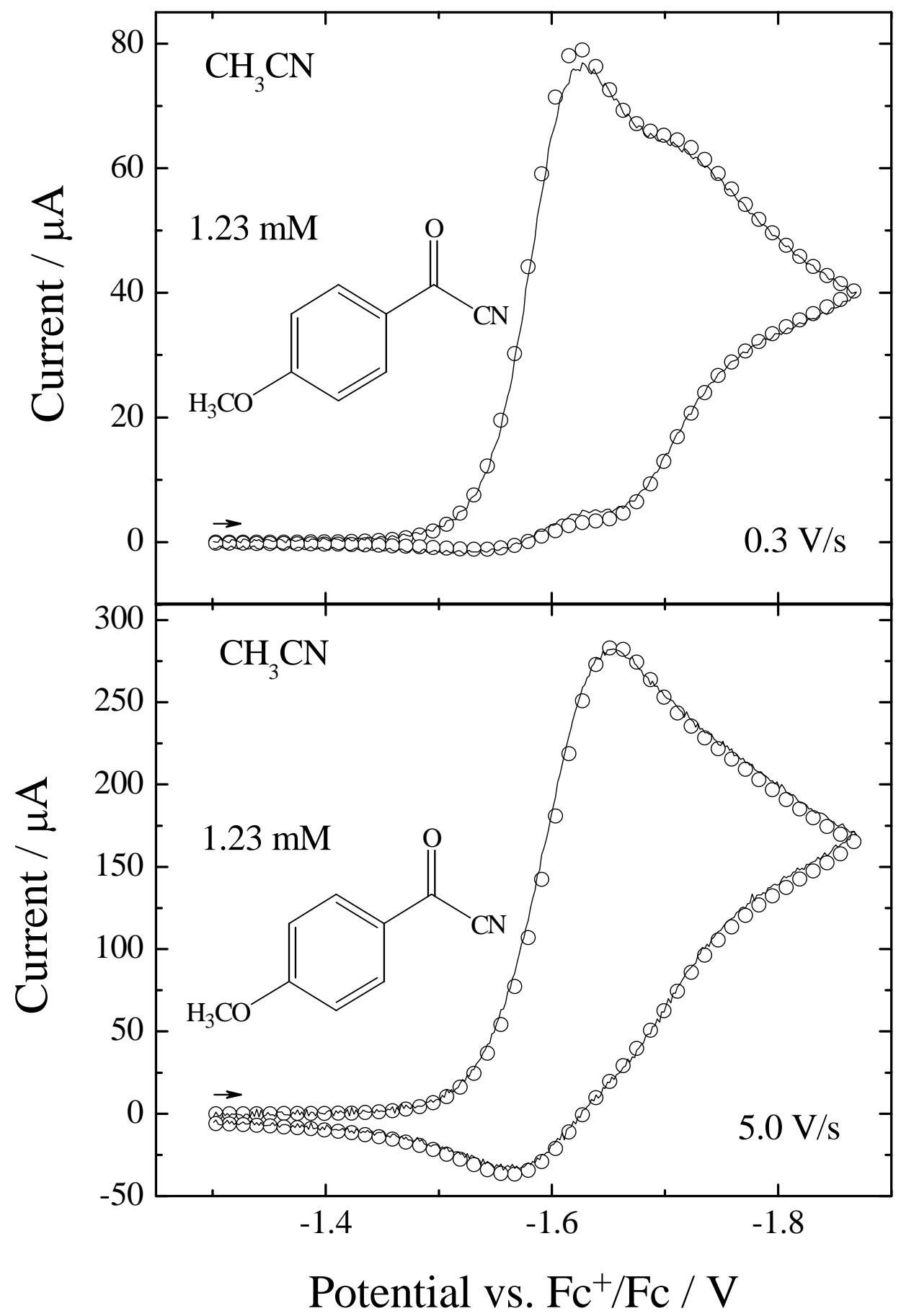

Figure S7 


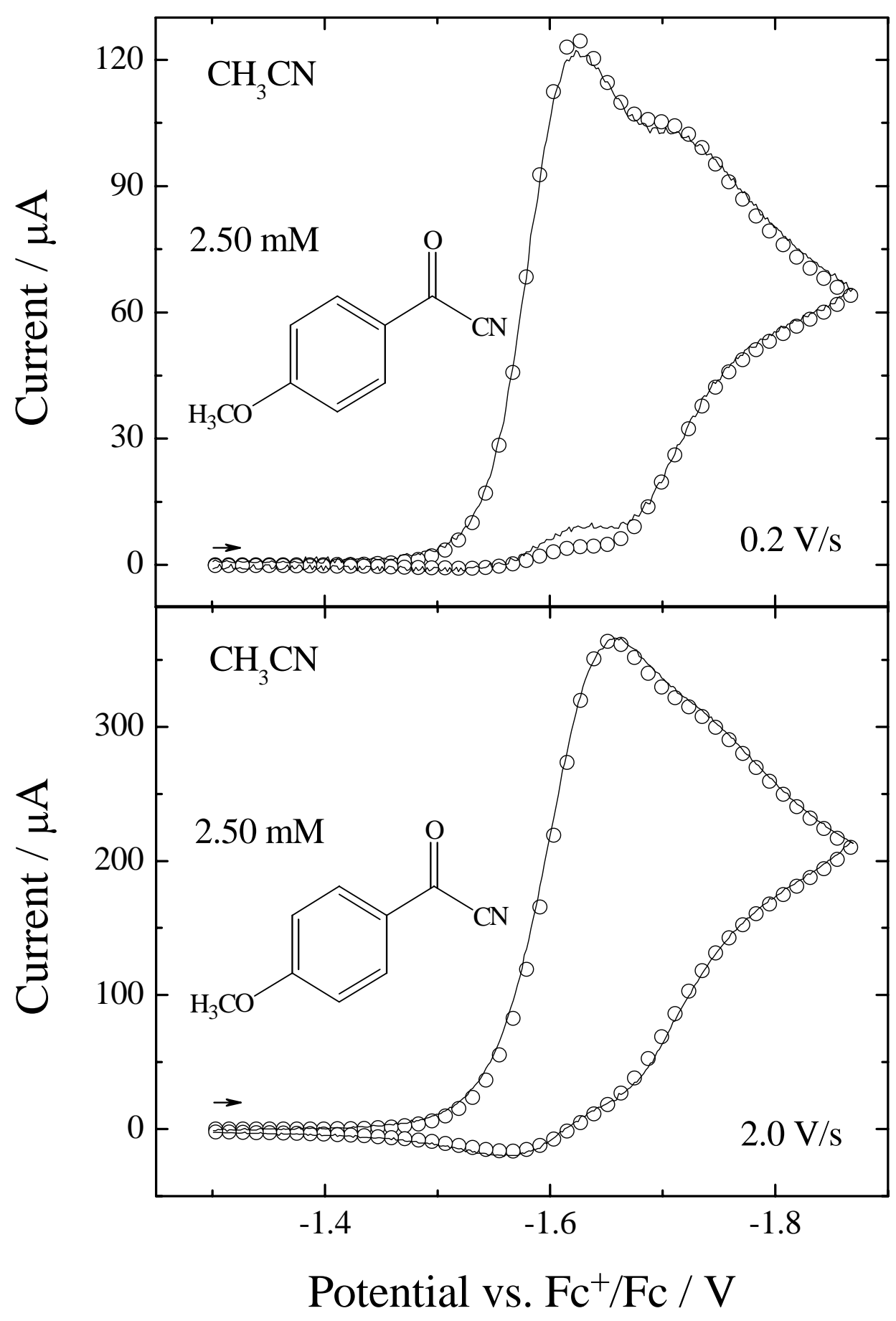

Figure S8 


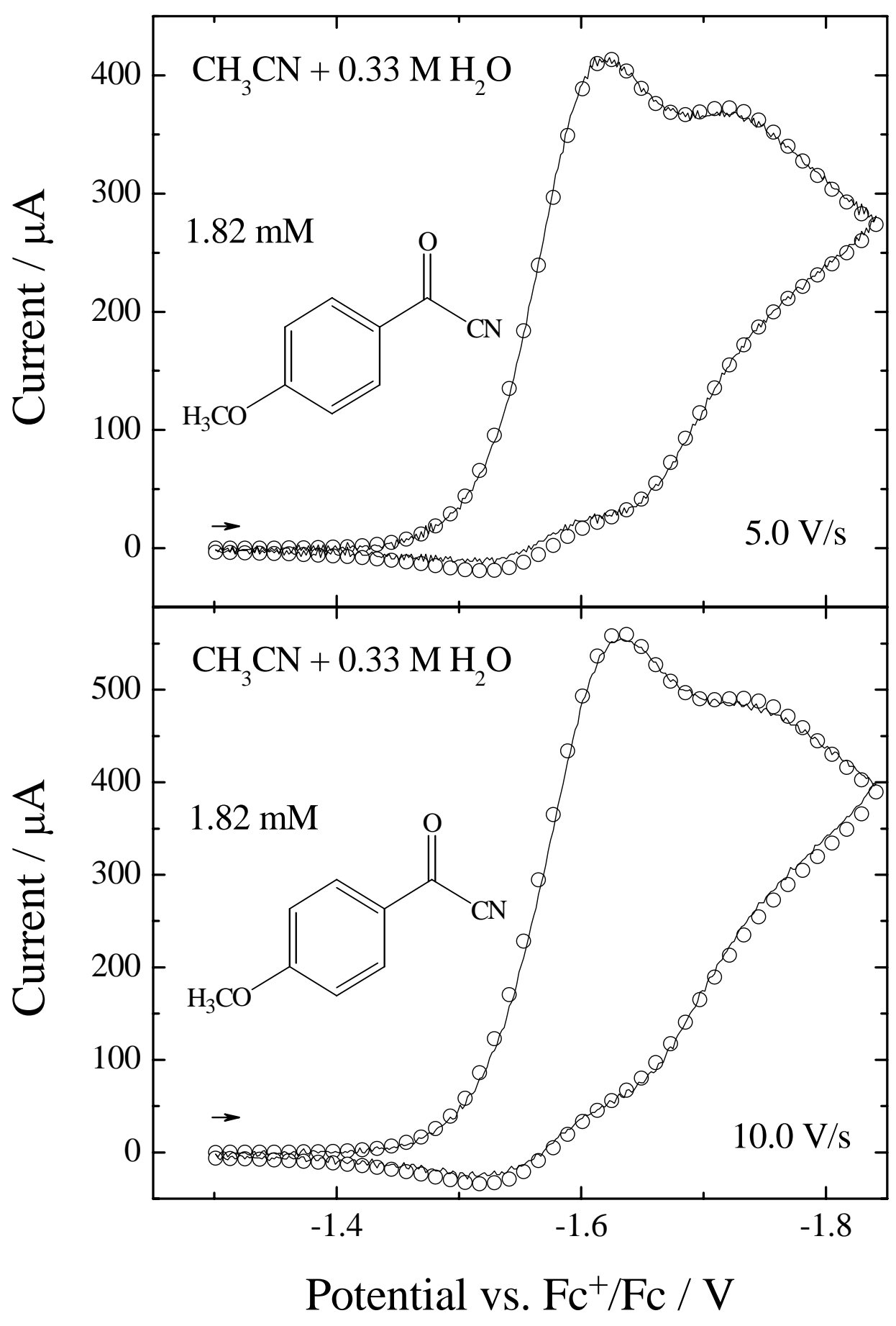

Figure S9 


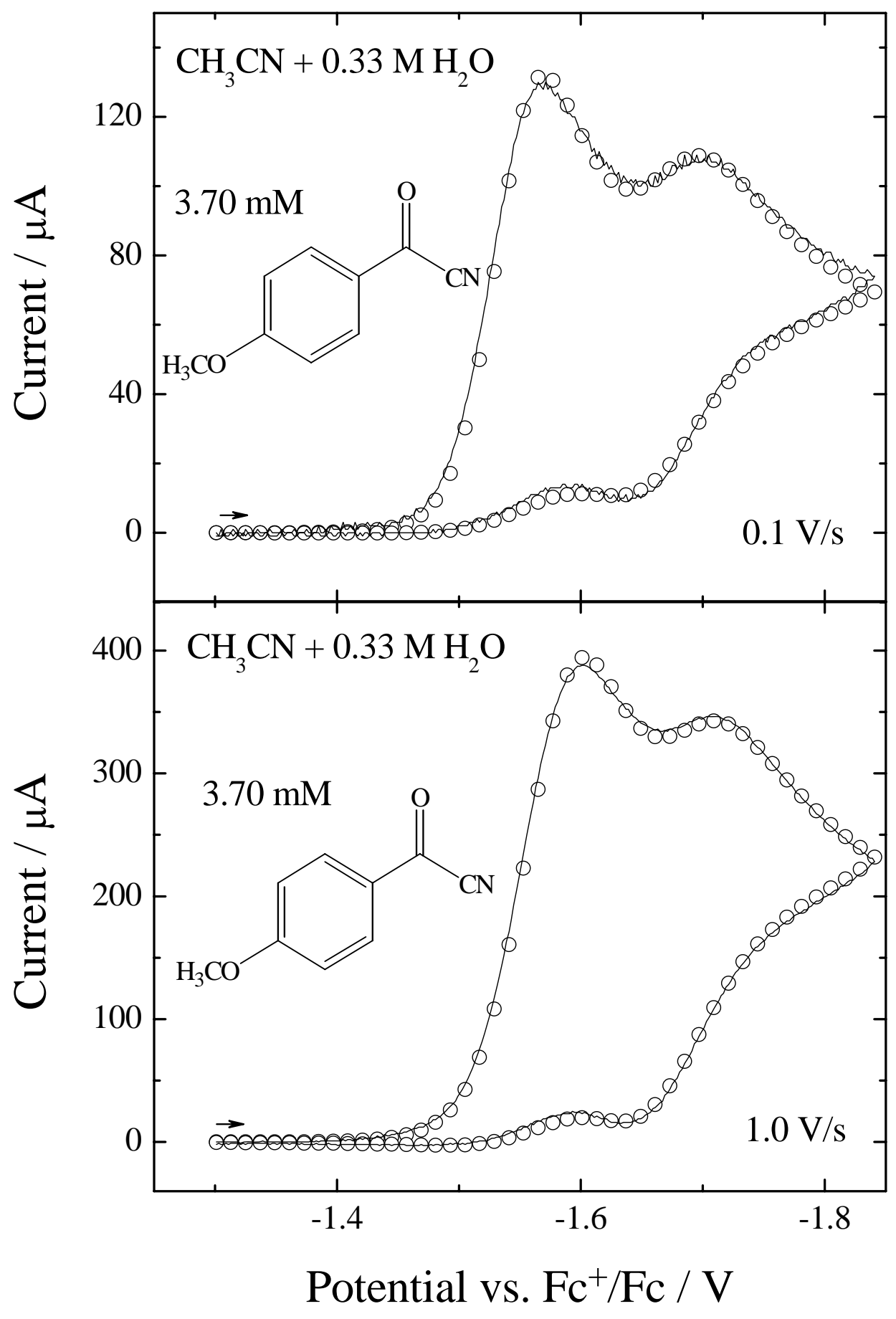

Figure S10 


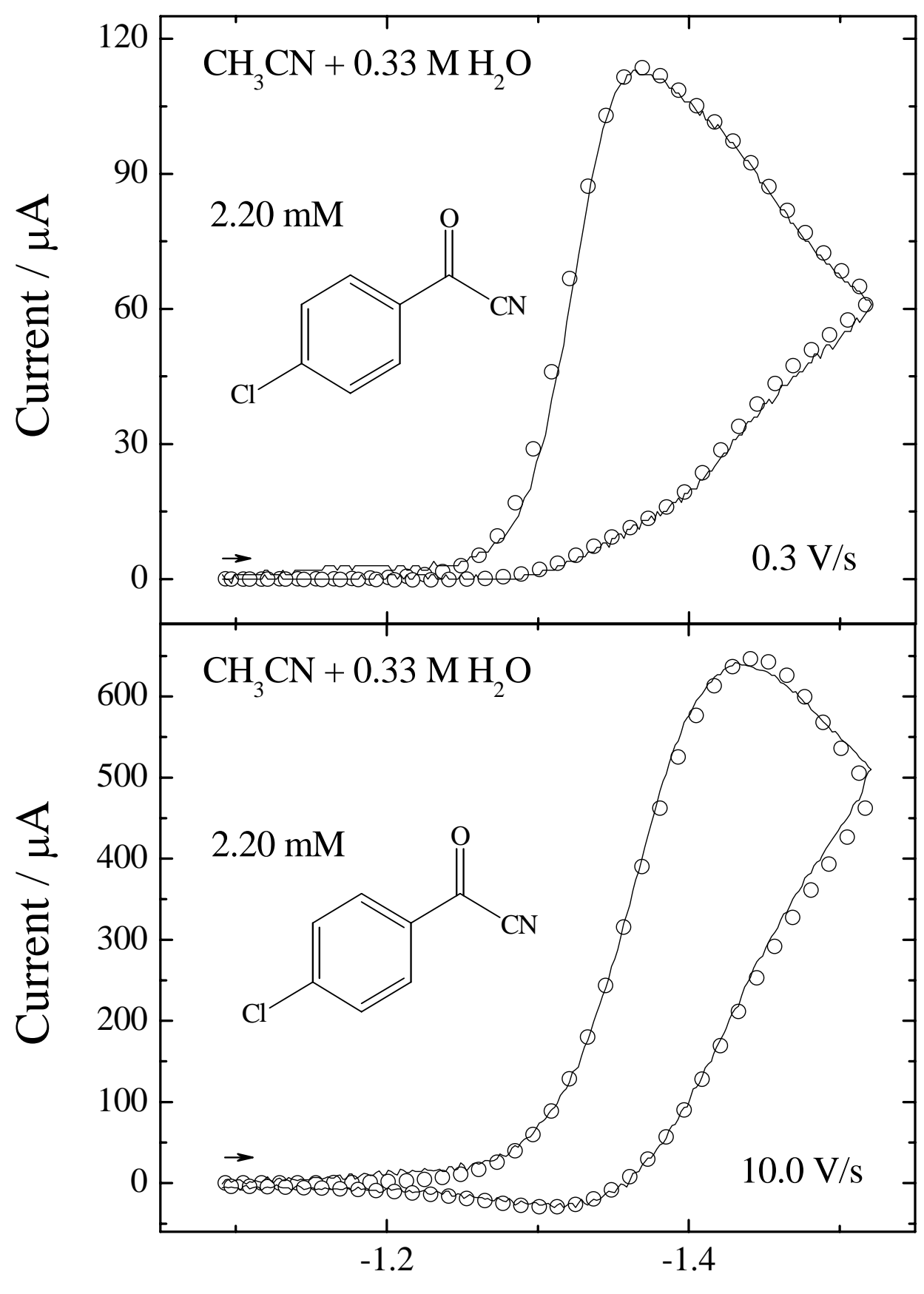

Potential vs. $\mathrm{Fc}^{+} / \mathrm{Fc} / \mathrm{V}$

Figure S11 


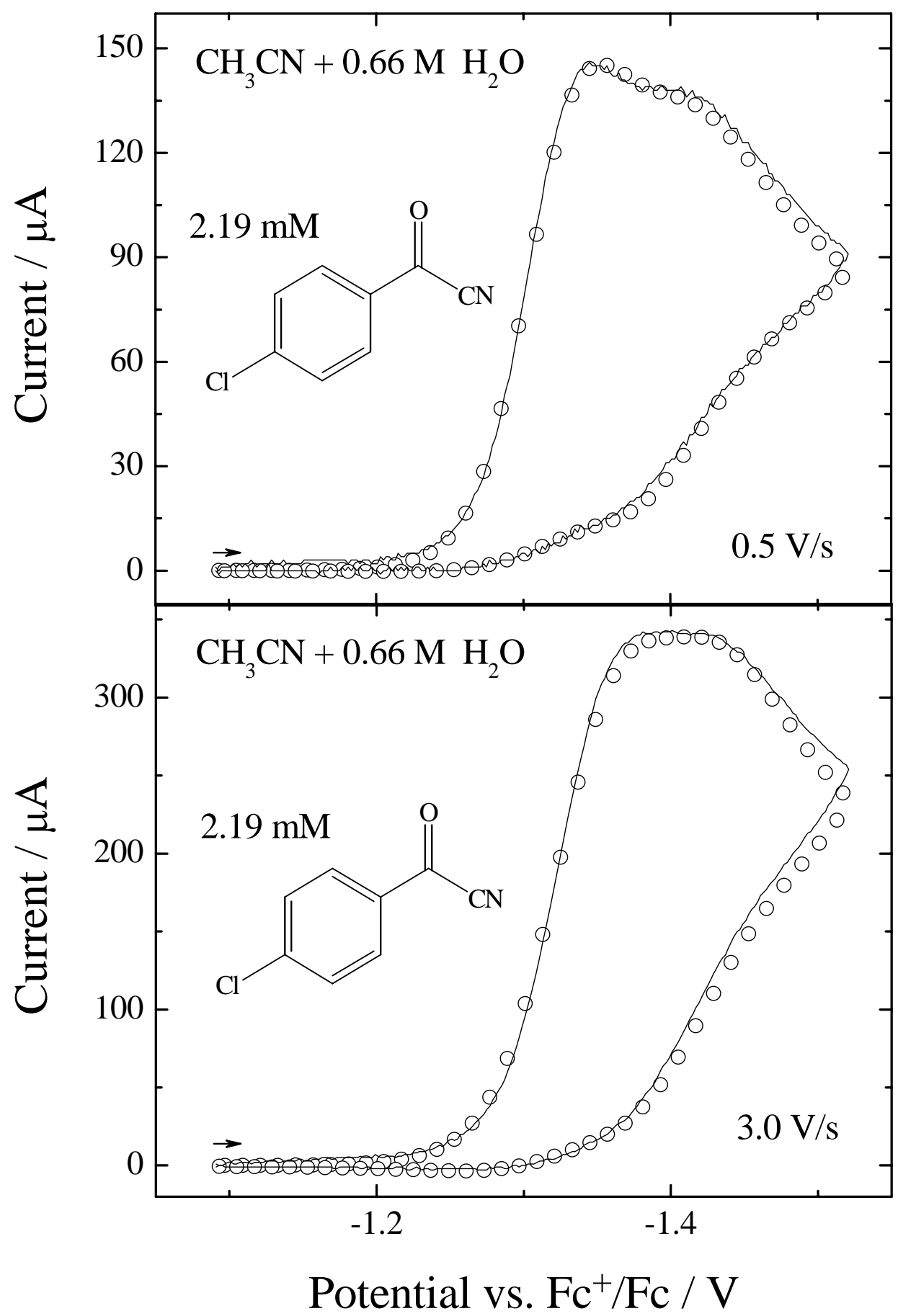

Figure S12 